\title{
Üst gis endoskopi yapılacak hastalarda alarm semptom varlığı ile organik patoloji arasındaki prediksiyon çalışması
}

\author{
A prediction study between patients with the presence of alarm symptoms and organic pathology in \\ upper gastrointestinal tract endoscopy
}

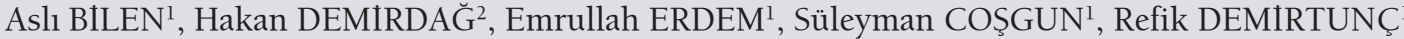 \\ ${ }^{1}$ Haydarpaşa Numune Eğitim ve Araştırma Hastanesi, Iç Hastalılan Kliniği, Istanbul \\ ${ }^{2}$ Ümraniye Eğitim ve Arasttrma Hastanesi, Gastroenteroloji Kliniŏi, Istanbul
}

Giriş ve Amaç: Dispepsili genç hastalarda alarm semptomlarının olmamas malignite yokluğuna dair güvenilir bir gösterge olarak kabul edilmektedir. Ancak alarm semptomlarının pozitif prediktif değeri nispeten zayıf kalmaktadır. Bu çalışmadaki amacımız alarm semptomlarının üst gastrointestinal sistem maligniteleri için tanısal değerini ve alarm semptomlarının yanısıra üst gastrointestinal sistem malignitelerini predikte eden farklı kriterlerler olup olmadığını araştırmaktır. Gereç ve Yöntem: 01.07.2011 ile 15.12.2012 tarihleri arasında Haydarpaşa Numune EAH Endoskopi Ünitesi'ne çeşitli nedenlerle üst gastrointestinal sistem endoskopisi yapılması amacıyla yönlendirilen 18-70 yaş arasında 200 hastaya hazırlamış olduğumuz anket yapılarak alarm semptomlarının olup olmadığı sorgulandı. Herhangi bir alarm semptomu varlığının ve tek tek alarm semptomlarının üst gastrointestinal sistem malignite prediksiyonu açısından duyarlılıkları, seçicilikleri, pozitif prediktif değerleri ve negatif prediktif değerleri hesaplandı. Bulgular: Çalışmada üst gastrointestinal sistem malignite prevalansı \%3.5 olarak bulundu. Malignite görülen olguların tamaminda herhangi bir alarm semptomu tespit edilirken, malignitesi olmayan olgularda alarm semptomu görülme oranı \%91.2 idi. Herhangi bir alarm semptomu varlığının ve her bir alarm semptomunun pozitif prediktif değeri düşük, negatif prediktif değeri yüksek saptandı. Maligniteli olgularn \%28'i iyi differansiye, \%28'i orta differansiye, \%44'ü az differansiye idi. Üst gastrointestinal sistem malignitesi ile kilo kaybı olan ve sarılık, abdominal kitle ya da lenfadenopati olan olgular arasında istatistiksel açıdan anlamlı ilişki saptandı. Malignite tanısına 45 yaş ve üstünde olmak, disfaji, kilo kaybı, anoreksi, sarılık ve gastrik cerrahi öykü parametrelerinin etkilerini lojistik regresyon analizi ile değerlendirdiğimizde malignite ile ilişkileri istatistiksel olarak anlamlı ( $p: 0.002$; p<0.01) bulundu. Sonuç: Sonuç olarak, bulgularımız alarm semptomlarının tanısal değerinin optimal olmadığını gösterdi. En etkin (alarm semptomlanı ve diğer faktörlerin) kombinasyonun tanımlanması için daha geniş olgu serilerine sahip çalışmalara ihtiyaç vardır.

Anahtar kelimeler: Malignite, endoskopi

\section{GİRISS}

Tip terimi olarak dyspepsia sindirim güçlüğüdür (Dys=zor, Pepsis=Sindirmek, pişirmek, difficult digestion). Bugünkü bilgilerimize göre dispepsi belli bir etyolojik faktöre bağlı olarak ortaya çıkan bir hastalık değildir. Etyolojisinden birçok faktör sorumlu tutulmaktadır. Bu nedenler sebebiyle dispepsi hastalıktan ziyade semptomlar kompleksidir. Bazı bilim adamları dispepsiyi bir sendrom olarak kabul etmektedirler (1).

Dispepsinin toplumda görülme sıklı̆ı \% 40 'lara varan oranlarda bildirilmekte ise de yaklaşık \%20-25 oranında olduğu kabul edilmektedir (1). Dispeptik yakınmalarla başvuran
Background and Aims: The absence of alarm symptoms in young patients with dyspepsia are considered to be safe markers for the absence of malignancy. However, the positive predictive value of alarm symptoms is weak, respectively. In this study, we aimed to evaluate the diagnostic value of alarm symptoms for upper gastrointestinal system malignancies and to determine if there are different criteria that predict upper gastrointestinal system malignancy as well as alarm symptoms. Materials and Methods: To evaluate the presence of alarm symptoms in patients undergoing upper gastrointestinal system endoscopy for various reasons, we prepared and administered a questionnaire in 200 patients, 18-70 years of age, who were seen at the Endoscopy Unit of Haydarpasa Numune Hospital between July 1, 2011 and Dec 15, 2012. Sensitivities, selectivities, and positive and negative predictive values of the presence of any alarm symptom were calculated to predict upper gastrointestinal system malignancy. Results: Prevalence of upper gastrointestinal system malignancy was found to be $3.5 \%$ in the study. Positive and negative predictive values for the presence of any alarm symptom, and each individual alarm symptom, were determined to be fewer and more, respectively. A statistically significant correlation was seen among upper gastrointestinal system malignancy and cases with weight loss, jaundice, abdominal mass or lymphadenopathy. Using logistic regression analysis, we analyzed the effects of the following parameters ( $\geq 45$ years of age, dysphagia, weight loss, anorexia, jaundice and gastric surgery history) in the diagnosis of malignancy; the relation with malignancy was found to be statistically significant ( $p: 0,002 ; p<0.01$ ). Conclusion: In conclusion, our results showed that the diagnostic value of alarm symptoms were less than optimal. A study of a larger case series is required to determine the most efficient combination of alarm symptoms and other factors.

Key words: Malignancy, endoscopy

olgulara ciddi bir araştırma yapıldığı zaman şu tablo ortaya çıkmaktadır. Olguların yaklaşık \%75'inde semptomları izah edecek organik-metabolik bir patoloji saptanmamaktadır (2). Olguların yaklaşı \%25'inde ise bir patolojik bulgu mevcuttur (2). Bunların \%13'ünde özofajitis, \%8'inde peptik ülser, \%1'inde Barrett özofagus, \%0,3'ünde üst gastrointestinal malignite tespit edilmiştir (2). Dispepsi bu kadar yaygın bir yakınma iken hangi hastaların üst gastrointestinal sistem (GIS) endoskopisine sevk edileceklerine karar vermek ve bunlardan hangilerinde ivedi davranılması gerektiği oldukça önemli bir husustur. 
The American College of Pysicians (ACP)'in 1985 yılında yayınladığı kılavuzda 45 yaşından büyük, dispepsi şikayeti olan hastaların ivedilikle endoskopiye sevk edilmeleri önerilmektedir (4). Bu stratejinin majör gerekçesi mide kanserinin 45 yaşın altındaki hastalarda oldukça nadir görülmesidir. Fakat bu oran giderek artmaktadır (5-7). Başka bir dataya göre mide kanserinin genç hastalarda seyrek görülmesi nedeniyle yaş sınırının 55'e çıkarılması önerilmiştir (8). Fakat fark edilmiştir ki sadece yaş sınırı dikkate alındığında az sayıda mide kanserli hasta atlanmaktadır (9). Ileri yaşa ek olarak diğer alarm semptomları Tablo l'de listelenmiştir.

\section{Tablo 1. Alarm semptomlarının dağılımları}

\begin{tabular}{|lcc|}
\hline 45 yaş ve üstü & n & \% \\
\hline Anemi/GİS kanama & 114 & 57,0 \\
\hline Disfaji/odinofaji & 75 & 37,5 \\
\hline Kilo kaybı & 51 & 25,5 \\
\hline Anoreksi/erken doyma & 55 & 27,5 \\
\hline Hematemez & 55 & 27,5 \\
\hline Melena & 12 & 6,0 \\
\hline Ailede mide Ca & 29 & 14,5 \\
\hline Tekrarlayan kusma & 17 & 8,5 \\
\hline Gece uykudan uyandıran dispepsi & 49 & 24,5 \\
\hline Aşırı NSAII alımı & 87 & 43,5 \\
\hline Sarılık, Abdominal kitle, LAP & 43 & 21,5 \\
\hline Gastrik Ca/gastrik cerrahi öykü & 5 & 2,5 \\
\hline
\end{tabular}

GIS: Gastrointestinal sistem.

NSAII: Non-steroid antiinflamatuvar ilaç. LAP: Lenfadenopati

Dispepsili genç hastalarda alarm semptomlarının olmaması malignite yokluğuna dair güvenilir bir gösterge olarak kabul edilmektedir $(6,10)$. Ancak alarm semptomlarının pozitif prediktif değeri nispeten zayıf kalmaktadır (11-13).

Bu çalışmadaki amacımız alarm semptomlarının üst GIS maligniteleri için tanısal değerini ve alarm semptomlarının yanısıra üst GIS maligniteyi predikte eden farklı kriterlerler olup olmadığını araştırmaktır. Hastanemiz polikliniklerinden çeşitli nedenlerle üst GIS endoskopi yapılması amacıyla endoskopi ünitesine yönlendirilen 18-70 yaş aralığında 200 hasta ile hazırlamış olduğumuz anket yapılarak alarm semptomlarının olup olmadığını sorguladık. Üst GIS endoskopi sonrası endoskopi raporları ve patoloji raporları değerlendirilerek, malignite ile uyumlu sonuçlar ile hastaların alarm semptomları tarif edip etmemesine bakıldı. Alarm semptomu varlığının malignite prediksiyonu açısından istatistiksel olarak anlamlı olup olmadığını, alarm semptomu ile kombine edilebilecek diğer faktörleri değerlendirmeyi amaçladık.

\section{GEREC ve YÖNTEM}

01.07.2011 ile 15.12.2012 tarihleri arasında Haydarpaşa Numune EAH Gastroenteroloji Servisi Endoskopi Ünitesi'ne çeşitli nedenlerle üst GIS endoskopisi yapılması amacıyla yönlendirilen 18-70 yaş arasında 200 hastaya hazırlamış olduğumuz anket yapılarak alarm semptomlarının olup olmadığı sorgulandı. Olguların yaş, cinsiyet, eğitim düzeyi, son 1 yılda endoskopi yapılıp yapılmadığı, acil istem olup olmadığı, Helicobacter pylori ( $\mathrm{Hp}$ ) eradikasyonu, kostik ajan alımı, siroz öyküsü, son 2 haftada proton pompası inhibitörü (PPI), antiasid, antibiyotik alımı, öntanıları, başvuru semptomları, alarm semptomlarının varlığı, hiç alarm semptomu olmaması, endoskopi ve patoloji sonuçları, (Hp) pozitifliği değerlendirildi. Herhangi bir alarm semptomu varlığının ve tek tek alarm semptomlarının üst GIS malignite prediksiyonu açısından duyarlılıkları, seçicilikleri, pozitif prediktif değerleri ve negatif prediktif değerleri hesaplandı.

Duyarlılık= Yeni test gerçek hastaların ne kadarını doğru saptiyor?

Seçicilik= Yeni test gerçek sağlamların ne kadarını doğru saptiyor?

Pozitif Prediktif Değer (PPD) = Yeni testin hasta dediklerinin altın teste göre ne kadarı hasta?

Negatif Prediktif Değer (NPD) = Yeni testin sağlam dediklerinin altın teste göre ne kadarı sağlam?

Çalışmada elde edilen bulgular değerlendirilirken, istatistiksel analizler için SPSS (Statistical Package for Social Sciences) for Windows 15.0 programı kullanıldı. Çalışma verileri degerlendirilirken tanımlayıcı istatistiksel metodların (Ortalama, Standart sapma, frekans) yanı sıra niteliksel verilerin karşlaştırılmasında Ki-Kare testi ve Fisher's Exact Ki-Kare testi kullanıldı. Multivariate analiz için lojistik analiz uygulandı. Anlamlılık p<0.05 düzeyinde değerlendirildi.

\section{BULGULAR}

Çalışma 01/07/2011-15/12/2012 tarihleri arasında yaşları 18 ile 70 arasında değissmekte olan toplam 200 olgu üzerinde yapılmıştır. Olguların ortalama yaşları 46.50土15.29 yıldır. Olguların \%45'i erkek, \%55'i kadındır. Olguların \%57'si 45 yaş ve üzerinde iken, \%43'ü 45 yaş altındadır. Olguların \%91.5'inde alarm semptomu tespit edilirken, \%8.5'inde hiçbir alarm semptomu saptanmamıştır. Olguların \%57'si 45 yaş ve üstüdür.

Olgularm \%37.5'inde anemi/GiS kanama, \%25.5'inde disfaji/ odinofaji, \%27.5'inde kilo kaybı, \%27.5'inde anoreksi/ erken doyma, \%6'sinda hematemez, \%14.5'inde melena, \%8.5'inde ailede mide ca, \%24.5'inde tekrarlayan kusma, \%43.5'inde gece uykudan uyandıran dispepsi, \%21.5'inde aşırı non-steroid antiinflamatuvar ilaç (NSAIII) alımı, \%2.5'inde sarılık, 


\begin{tabular}{|c|c|c|c|}
\hline \multirow{2}{*}{ Alarm semptomu } & & gnite & \\
\hline & Var n (\%) & Yok n (\%) & $\mathrm{p}$ \\
\hline Var & $7(\% 100,0)$ & $176(\% 91,2)$ & 1,000 \\
\hline Yok & $0(\% 0)$ & $17(\% 89,8)$ & \\
\hline
\end{tabular}

Fisher's Exact test

abdominal kitle, lenfadenopati (LAP) ve \%3.5'inde gastrik $\mathrm{Ca/gastrik} \mathrm{cerrahi} \mathrm{öykü} \mathrm{semptomuna} \mathrm{rastlanmıştır.} \mathrm{Olguların}$ \%3.5'inde malignite görülmüştür. Malignite görülen olgularnn tamaminda herhangi bir alarm semptomu tespit edilirken, malignitesi olmayan olgularda alarm semptomu görülme oranı \%91.2'dir ve aralarında istatistiksel olarak anlamlı bir farklllık bulunmamaktadır ( $>0.05$ ) (Tablo 2).

Malignite tespit edilen olguların 45 yaş ve üstünde olma oranları (\%85.7), benign olan olguların 45 yaş ve üstü olma oranlarından (\%56) daha yüksek olmakla birlikte bu farklılık istatistiksel olarak anlamlı bulunmamıştır ( $>>0.05$ ). Aralarındaki farklılık anlamlı bulunmamakla birlikte 45 yaş ve üzeri olgularda malignite riski 4.722 kat fazladır (Odds ratio: 4.722; \%95 CI:0.558-39.976).

Malignite ile anemi/GIS kanama arasında istatistiksel olarak anlamlı bir ilişki bulunmamaktadır ( $\mathrm{p}>0.05$ ). Malignitesi olan olgularda anemi/GIS kanama görülme oranı \%28.6 iken, benign olan olgularda bu oran \%37.8'dir (Odds Ratio: 0.658; \%95 CI:0.124-3.477).

Malignite ile disfaji/odinofaji arasında anlamllığa yakın olmakla birlikte istatistiksel olarak anlamlı bir ilişki bulunmamaktadır ( $p>0.05$ ). Anlamlı bir ilişki bulunmamakla birlikte, malignitesi olan olgularda disfaji/odinofaji görülme oranının (\%57.1), benign olan olgulardan (\%24.4) daha yüksek oluşu dikkat çekicidir. Disfaji/odinofaji görülen olgularda malignite riski 4.142 kat fazladır (Odds ratio: 4.142; \%95 CI:0.89519.178).

Malignite ile kilo kaybı arasında istatistiksel olarak anlamlı bir ilişki bulunmaktadır $(\mathrm{p}<0.05)$. Malignite tespit edilen olgularda kilo kaybı görülme oranı (\%71.4), benign olan olgulardan (\%25.9) anlamlı şekilde yüksektir. Kilo kaybı malignite riskini 7.150 kat arttırmaktadır (Odds ratio: 7.150; \%95 CI:1.344-38.025) (Tablo 3).

Malignite ile anoreksi arasında anlamlılığa yakın olmakla birlikte istatistiksel olarak anlamlı bir ilişki bulunmamaktadır ( $>0.05)$. Anlamlı bir ilişki bulunmamakla birlikte, malignite tespit edilen olgularda anoreksi görülme oranının (\%57.1), benign olan olgulardan (\%26.4) daha yüksek oluşu dikkat çekicidir. Anoreksi görülen olgularda malignite riski 3.712 kat fazladır (Odds ratio: 3.712; \%95 CI:0.803-17.158). Malignite ile hematemez arasında istatistiksel olarak anlamlı bir ilişki bulunmamaktadır ( $\mathrm{p}>0.05)$.
Malignite ile melena arasında istatistiksel olarak anlamlı bir ilişki bulunmamaktadır (p>0.05) (Odds Ratio: 0.982; \%95 CI:0.114-8.470).

Malignite ile ailede mide ca olması arasında istatistiksel olarak anlamlı bir ilişki bulunmamaktadır ( $p>0.05$ ). Malignitesi olan olguların ailelerinde mide ca görülme oranı \%14.3 iken, benign olan olgularda bu oran \%8.3'tür (Odds ratio: 1.844; \%95 CI:0.209-16.277).

Malignite ile tekrarlayan kusma arasında istatistiksel olarak anlamlı bir ilişki bulunmamaktadır ( $p>0.05)$. Malignitesi olan olgularda kusma görülme oranı \%42.9 iken, benign olan olgularda bu oran \%23.8'dir (Odds ratio: 2.397; \%95 CI:0.517-11.103).

Malignite ile gece uykudan uyandıran dispepsi arasında istatistiksel olarak anlamlı bir ilişki bulunmamaktadır ( $>0.05$ ). Malignitesi olan olgularda gece uykudan uyandıran dispepsi görülme oranı \%57.1 iken, benign olan olgularda bu oran \%43’tür (Odds ratio: 1.767; \%95 CI:0.385-8.110).

Malignite ile aşırı NSAII alımı arasında istatistiksel olarak anlamlı bir ilişki bulunmamaktadır ( $>>0.05)$. Malignitesi olan olgularda aşırı NSAIl alımı oranı \%14.3 iken, benign olan olgularda bu oran \%21.8'dir (Odds ratio: 0.599; \%95 CI:0.070-5.116).

Tablo 3. Malignite ile alarm semptomlarının ilişkisi

\begin{tabular}{llll}
\hline & \multicolumn{3}{c}{ Malignite } \\
& Var n (\%) & Yok n (\%) & p \\
\hline 45 yaş ve üstü & $6(\% 85,7)$ & $108(\% 56,0)$ & 0,242 \\
\hline Anemi/Gis kanama & $2(\% 28,6)$ & $73(\% 37,8)$ & 0,713 \\
\hline Disfaji/odinofaji & $4(\% 57,1)$ & $47(\% 24,4)$ & 0,072 \\
\hline Kilo kaybı & $5(\% 71,4)$ & $50(\% 25,9)$ & $0,018^{*}$ \\
\hline $\begin{array}{l}\text { Anoreksi/ } \\
\text { erken doyma }\end{array}$ & $4(\% 57,1)$ & $51(\% 26,4)$ & 0,092 \\
\hline Hematemez & $0(\% 0,0)$ & $12(\% 6,2)$ & 1,000 \\
\hline Melena & $1(\% 14,3)$ & $28(\% 14,5)$ & 1,000 \\
\hline $\begin{array}{l}\text { Ailede mide Ca } \\
\text { Tekrarlayan kusma }\end{array}$ & $1(\% 14,3)$ & $16(\% 8,3)$ & 0,468 \\
\hline $\begin{array}{l}\text { Gece uykudan } \\
\text { uyandıran dispepsi }\end{array}$ & $4(\% 57,1)$ & $83(\% 43,0)$ & 0,471 \\
\hline Aşırı NSAII alımı & $1(\% 14,3)$ & $42(\% 21,8)$ & 1,000 \\
\hline $\begin{array}{l}\text { Sarılık, } \\
\text { Abdominal kitle, LAP }\end{array}$ & $2(\% 28,6)$ & $3(\% 1,6)$ & $0,011^{*}$ \\
\hline $\begin{array}{l}\text { Gastrik Ca/ } \\
\text { gastrik cerrahi öykü }\end{array}$ & $1(\% 14,3)$ & $6(\% 3,1)$ & 0,224 \\
\hline
\end{tabular}

Fisher's Exact test * $\mathrm{p}<0.05$.

GIS: Gastrointestinal sistem.

NSAIt: Non-steroid antiinflamatuvar ilaç. LAP: Lenfadenopati 
Tablo 4. Alarm semptomlarının lojistik regresyon analizi sonucu

$\begin{array}{lccccc}\text { Step } 4 & B & \text { S.E. } & p & \text { Odds Ratio } & \% 95 \text { CI } \\ \text { 45 yaş ve üstü } & -1,675 & 1,166 & 0,151 & 0,187 & 0,019-1,840 \\ \text { Kilo kaybı } & -1,770 & 0,895 & 0,048^{*} & 0,170 & 0,029-0,985 \\ \text { Sarılık, abdominal kitle, LAP } & -3,016 & 1,170 & 0,011^{*} & 0,049 & 0,005-0,485\end{array}$

Modele konulan parametreler: Yaş, disfaji, kilo kaybl, anoreksi, sarlık ve gastrik cerrahi öykü LAP: Lenfadenopati

\section{Tablo 5. Alarm semptomlarının sensitivite, spesifite, pozitif prediktif değer ve negatif prediktif değerleri}

\begin{tabular}{|c|c|c|c|c|}
\hline & Sensitivite & Spesifite & PPD & NPD \\
\hline Herhangi bir alarm semptomu olanlar & $\% 100$ & $\% 8.8$ & $\% 3.8$ & $\% 100$ \\
\hline$\geq 45$ yaş & $\% 85$ & $\% 45$ & $\% 5.3$ & $\% 98$ \\
\hline Anemi/GIS kanama & $\% 28$ & $\% 62$ & $\% 2.6$ & $\% 96$ \\
\hline Disfaji/Odinofaji & $\% 57$ & $\% 75$ & $\% 7.8$ & $\% 97$ \\
\hline Kilo kaybı & $\% 71$ & $\% 74$ & $\% 9$ & $\% 98$ \\
\hline Anoreksi/Erken doyma & $\% 57$ & $\% 73$ & $\% 7.2$ & $\% 97$ \\
\hline Hematemez & $\alpha$ & $\% 93$ & $\alpha$ & $\% 96$ \\
\hline Melena & $\alpha$ & $\% 84$ & $\alpha$ & $\% 95$ \\
\hline Ailede mide $\mathrm{Ca}$ & $\% 14$ & $\% 91$ & $\% 5.8$ & $\% 96$ \\
\hline Tekrarlayan kusma & $\% 42$ & $\% 76$ & $\% 6.1$ & $\% 97$ \\
\hline Gece uyandıran dispepsi & $\% 57$ & $\% 56$ & $\% 4.6$ & $\% 97$ \\
\hline NSAIt aşırı alımı & $\% 14$ & $\% 78$ & $\% 2.3$ & $\% 96$ \\
\hline Sarılık/Abdominal kitle & $\% 28$ & $\% 98$ & $\% 40$ & $\% 97$ \\
\hline Gastrik cerrahi öyküsü & $\% 14$ & $\% 96$ & $\% 14$ & $\% 96$ \\
\hline
\end{tabular}

$\alpha$ : Malignite sayısı 0 olduğundan hesaplanamadı.

PPD: Pozitif prediktif değer. NPD: Negatif prediktif değer. GIS: Gastrointestinal sistem. NSAII: Non-steroid antiinflamatuvar ilaç.

Malignite ile sarılık, abdominal kitle, lenfadenopati varlı̆̆ arasında istatistiksel olarak anlamlı bir ilişki bulunmaktadır ( $\mathrm{p}<0.05)$. Malignite tespit edilen olan olgularda sarılık, abdominal kitle, lenfadenopati görülme oranının (\%28.6), bening olan olgulardan (\%1.6) anlamlı şekilde yüksektir. Sarılık, abdominal kitle, lenfadenopati malignite riskini 25.333 kat arttırmaktadır (Odds ratio: 25.333; \%95 CI:3.437-186.709).

Malignite ile gastrik cerrahi öykü arasında istatistiksel olarak anlamlı bir ilişki bulunmamaktadır ( $>>0.05)$. Anlamlı bir ilişki bulunmamakla birlikte, malignitesi olan olgularda gastrik cerrahi öykü oranının (\%14.3) iken, benign olan olgulardan (\%3.1) daha yüksek oluşu dikkat çekicidir. Gastrik cerrahi öyküsü olan olgularda malignite riski 5.194 kat fazladır (Odds ratio: 5.194; \%95 CI:0.538-50.164). Malignite tanısına 45 yaş ve üstünde olmak, disfaji, kilo kaybı, anoreksi, sarllık ve gastrik cerrahi öykü parametrelerinin etkilerini Backward stepwise lojistik regresyon analizi ile değerlendirdiğimizde; 4. stepte modelin ileri düzeyde anlamlı (p:0.002; $\mathrm{p}<0.01$ ) bulunduğu ve Negelkerke R square değerinin 0.321 olarak saptandığı, modelin açıklayıcılık katsayısının (\%96.5) iyi düzeyde olduğu görüldü. Modele kilo kaybı ve sarılık, abdominal kitle varlığının etkileri istatistiksel olarak önemli bulunmuştur $(p<0.05)$. 45 yaş ve üzerinde olmanın modele etkisi istatistiksel olarak anlaml bulunmamakla birlikte ( $p>0.05$ ); yaşın da modelde kaldığı ve maligniteyi arttırıcı etkisi olduğu görülmektedir.

\section{TARTIŞMA}

Alarm semptomları genellikle doğrudan üst GIS endoskopiye sevketmek için bir endikasyon olarak kabul edilir. Bu çeşitli kılavuzlara dispeptik semptoları olan hastaların tedavi ve triajının değerlendirilmesinde önemli kriterler olarak yansımiştır (12,13-15). Fakat üst GIS malignite riski taşıyan hastaların seçiminde alarm semptomlarının yararlılı̆̆ nadiren sorgulanır. Çalışmamızda alarm semptomlarının tanısal değerini ve alarm semptomlarının yanısıra üst GIS maligniteyi predikte eden farklı kriterlerler olup olmadığını sorgulamayı amaçladik. 
Yapılan çalışmalar göstermiş ki alarm semptomlarının olması ya da hiç alarm semptomunun olmaması ayrı ayrı malignite göstergesi olarak yeterli değildir (16). Alarm semptomlarının toplumdaki prevelansı oldukça yüksektir. Meineche-Schmidt ve Jorgensen'in yaptığı çalışmada dispeptik semptomlarla birinci basamak hekimine başvuran hastaların \%10'u bir ya da daha fazla alarm semptomu tarif etmektedir ve tetkik edildiklerinde bunlardan sadece \%3'ünde kanser saptanmıştır (17). Bu çalışmada 199 hastanın 183'ü alarm semptomları tarif ediyordu. Bunlardan 7 tanesinde üst GIS malignite tespit edildi. Malignite görülen olguların tamamında herhangi bir alarm semptomu tespit edilirken, malignitesi olmayan olgularda alarm semptomu görülme oranı \%91.2 idi. Fransen GAJ ve ark.nın yaptığı metaanaliz ile uyumlu olarak bizim çalışmamızda da herhangi bir alarm semptomu varlığının ve her bir alarm semptomunun pozitif prediktif değeri düşük, negatif prediktif değeri yüksek saptandı (16). Bu da gösteriyorki alarm semptomları olan hastaların yalnızca küçük bir kısmında kanser mevcuttur. Buna rağmen alarm semptomu tarif etmeyen hastalarda üst GIS malignitenin atlanma ihtimali oldukça düşüktür.

Başka bir hususta, çalışmamızda üst GIS malignite görülme oranı \%3.5 olarak tespit edildi. Oysaki bu oran literatürde Asya çalışmalarında ortalama \%0.3, batı çalışmalarında ise \%0.2 civarındadır (18). Bu durum hekim muayene ve triajıyla ön tanı olarak malignite düşünülen hastaların endoskopiye yönlendirilmeleri ve çalışmanın bu triajdan geçerek gelen hastalar dahil edilerek yapılmasından kaynaklandığı düşünülebilir.

Yine çeşitli çalışmalara göre üst GIS maligniteli hastalarda alarm semptomlarının ortaya çıkışı ileri evre kötü prognozlu kanserin göstergesidir (19-22). Bu nedenle alarm semptomu olan hastalarm ivedilikle endoskopiye sevk edilmelerinin prognoz üzerine iyileştirici etkisi olup olmadığı sorgulanabilir. Martin ve ark.nın 1997 yılında yaptığı çalışmada gastrik kanser tanısındaki gecikmenin prognoz ile ilişkisi olmadığı sonucu ortaya çıkmıştır (23). Ne yazık ki çalışmamızda malignite tespit edilen olguların kanser evreleriyle ilgili ayrıntılı bilgiye sahip değiliz ve bununla ilgili altgrup analizleri yapmamız mümkün olmamıştır. Fakat differansiyasyon açısından değerlendirmek gerekirse maligniteli olguların \%28'i iyi differansiye, \%28'i orta differansiye, \%44'ü az differansiye idi. Differansiyasyon açısından anlamlı fark olmaması alarm semptomlarının ortaya çıktığı andaki kanser differansiyasyonu açısından yorum yapmayı zorlaştırmaktadır.

\section{KAYNAKLAR}

1. Özden A. Dispepsi. Gastroenteroloji. 2002;105:85-93.a

2. Özden A. Dispepsi. Güncel Gastroenteroloji. 2012;118:273-282.

3. Fielding JWL, Ellis DJ, Jones BG, et al. Natural history of "early" gastric cancer: results of a 10-year regional survey. BMJ. 1980; 281: 965-7.
Alarm semptomlarının malignite ile ilişkisini her bir alarm semptomu için ayrı ayrı değerlendirmek gerekirse; üst GIS malignite ile kilo kaybı olan ve sarılık, abdominal kitle ya da lenfadenopati olan olgular arasında istatistiksel açıdan anlamlı ilişki saptandı. Bununla birlikte malignite riskinin; 45 yaş ve üzeri olgularda 4.72 kat, disfaji ya da odinofaji tarif eden olgularda 4.14 kat, anoreksi ya da erken doyma tarif eden olgularda 3.71 kat, gastrik cerrahi öyküsü olan olgularda 5.19 kat artmıs olması ihmal edilemeyecek bulgulardır. Malignite tanısına 45 yaş ve üstünde olmak, disfaji, kilo kaybı, anoreksi, sarılık ve gastrik cerrahi öykü parametrelerinin etkilerini lojistik regresyon analizi ile değerlendirdiğimizde malignite ile ilişkilerinin istatistiksel olarak anlamlı (p:0.002; p<0.01) bulunması, alarm semptomlarının birlikte bulunmasının malignite prediksiyonunu artıracağı düşünüldüğünde beklenen bir sonuçtur. Literatürde 45 yaş ve üstü olmak, erkek cinsiyet ve anemi ya da GIS kanama öyküsü kombinasyonu değerlendirildiğinde üst GIS malignite prediksiyonundaki sensitivitesinin \%91 ve spesifitesinin \%77'ye ulaştığını gösteren çalışmalar mevcuttur (24). Bu da üst GIS malignite açısından yüksek riskli hastaların seçiminde alarm semptomlarının farklı faktörlerle kombinasyonunun daha etkin bir yöntem olduğunu gösterir. Bu amaçla olguların cinsiyet, eğitim düzeyi, Hp eradikasyonu öyküsü, siroz öyküsü, kostik ajan öyküsü ile üst GİS malignite arasında ilişki olup olmadığını değerlendirdik. Fakat çalışmamızda siroz öyküsünün malignite riskini 7.87 kat artırması dışında istatistiksel olarak anlamlı sonuçlara ulaşılamadı. Bunun nedeni üst GIS malignite gibi nadir görülen bir hastalıkta prospektif bir çalışmada anlamlı sonuçlara ulaşılabilmesi için çok geniş bir hasta popülasyonuna ihtiyaç duyulmasından kaynaklanır.

Sonuç olarak, alarm semptomları genellikle doğrudan üst GIS endoskopiye sevketmek için bir endikasyon olarak kabul edilir. Fakat bulgularımız alarm semptomlarının tanısal değerinin optimal olmadığını gösterdi. Üst GİS malignite açısından yüksek riskli hastaların seçiminde iyi bir anamnez, fizik muayene yapılması, alarm semptomlarının varlığının, süresinin ve cinsiyet, $H p$ eradikasyonu öyküsü, kostik ajan alım öyküsü, siroz öyküsü, sigara ve alkol kullanımı, vs. gibi diğer faktörlerle kombine kullanımı önerilebilir. En etkin (alarm semptomları ve diğer faktörlerin) kombinasyonun tanımlanması için daha geniş vaka serilerine sahip çalışmalara ihtiyaç vardir.

4. Health and Public Policy Committee, American College of Physicians. Endoscopy in the evaluation of dyspepsia. Ann Intern Med. $1985 ; 102: 266-269$

5. Talley NJ, Silverstein MD, Agreus L, et al. AGA technical review: evaluation of dyspepsia. Gastroenterology. 1998;114:582-595. 
6. Bytzer P, Talley NJ. Dyspepsia. Ann Intern Med. 2001;134:815-822

7. Voutilainen M, Mantynen T, Kunnamo I, et al. Impact of clinical symptoms and referral volume on endoscopy for detecting peptic ulcer and gastric neoplasms. Scand J Gastroenterol. 2003;38:109-113.

8. Gillen D, McColl KE. Does concern about missing malignancy justify endoscopy in uncomplicated dyspepsia in patients aged less than 55? Am J Gastroenterol. 1999;94:2329-2330.

9. Talley NJ, Axon A, Bytzer P, et all. Management of uninvestigated and functional dyspepsia: a Working Party report for the World Congresses of Gastroenterology 1998. Aliment Pharmacol Ther. 1999;13:11351148 .

10. Gillen D, McColl KE. Does concern about missing malignancy justify endoscopy in uncomplicated dyspepsia in patients aged less than 55? Am J Gastroenterol. 1999;94:2329-2330.

11. Locke GR 3rd, Talley NJ, Fett SL, et all. Prevalence and clinical spectrum of gastroesophageal reflux: a population-based study in Olmsted County. Gastroenterology. 1997;112:1448-1456.

12. British Society of Gastroenterology (BSG). Dyspepsia Management Guidelines. London. BSG. 1996

13. Anonymous. Helicobacter pylori in peptic ulcer disease. NIH Consens Statement. 1994; 12: 1-23.

14. Malfertheiner P, Megraud F, O'Morain C, et al. Current concepts in the management of Helicobacter pylori infection - the Maastricht 2-2000 Consensus Report. Aliment Pharmacol Ther. 2002; 16: 167-80.

15. European Society for Primary Care Gastroenterology. The management of H. pylori in primary care. J Fam Pract. 2000; 17( 2): 1-35.
16. Fransen GAJ , Janssen MJR, Muris JWM, et al. Meta-analysis: the diagnostic value of alarm symptoms for upper gastrointestinal malignancy. Aliment Pharmacol Ther. 2004; 20: 1045-1052.

17. Meineche-Schmidt V, Jorgensen T. 'Alarm symptoms' in dyspepsia: How does the general practitioner investigate? Scand J Prim Health Care. 2003; $21: 224-9$.

18. Talley NJ. Dyspepsia. Gastroenterology. 2003; 125: 1219-1226

19. Boldys H, Marek TA, Wanczura P, et al. Even young patients with no alarm symptoms should undergo endoscopy for earlier diagnosis of gastric cancer. Endoscopy. 2003; 35: 61-7.

20. Hindmarsch A, Cheong E, Rees L, et al. National referral guidelines for cases of suspected upper GI cancer in the UK: are they working? Gut. 2003; 52 (VI): Al7.

21. Ahmad I, Azam A. To assess the effectiveness of two-week referrals for oesophageal and gastric cancer in accordance with united Kingdom department of health guidelines. Gut. 2003; 52 (VI): Al7.

22. Kubota H, Kotoh T, Masunaga R, et al. Impact of screening survey of gastric cancer on clinicopathological features and survival: retrospective study at a single institution. Surg. 2000; 128: 41-7.

23. Siersema PD, Dees J, Tilanus HW, et al. Early detection and treatment of oesophageal and gastric cancer. Neth J Med. 1995; 47: 76-86.

24. Martin IG, Young S, Sue-Ling H, et al. Delays in the diagnosis of oesophagogastric cancer: a consecutive case series. BMJ. 1997; 314: 467-70. 